\title{
PELATIHAN PEMBUATAN PRESENTASI INTERAKTIF UNTUK WARGA DAN PERANGKAT DESA KARANGDUREN, KEC.PAKISAJI, KAB. MALANG
}

\author{
Yuri Ariyanto ${ }^{1}$, Atiqah Nurul Asri ${ }^{2}$, Dwi Puspitasari ${ }^{3}$, Yoppy Yunhasnawa ${ }^{4}$, Bagas Satya Dian \\ Nugraha $^{5}$ \\ 1,2,3,4,5 Jurusan Teknologi Informasi, Teknik Informatika \\ e-mail: 1yuri@polinema.ac.id, ${ }^{2}$ atiqah.nurul@polinema.ac.id, ${ }^{3} \mathrm{dwi}$ sti@polinema.ac.id, \\ 4yunhasnawa@polinema.ac.id, ${ }^{5}$ bagas@polinema.ac.id
}

\begin{abstract}
Abstrak
Di tingkat desa, banyak kendala yang dihadapi aparatur pemerintahan desa dalam upaya memberikan pelayanan pada masyarakatnya. Satu diantaranya yang kini menonjol adalah hambatan yang terkait dengan kurangnya pengetahuan dan keterampilan pemanfaatan teknologi informasi dan komunikasi, khususnya aplikasi untuk pembuatan presentasi interaktif. Didasari kenyataan itulah maka gagasan untuk melaksanakan kegiatan PKM (Pengabdian Kepada Masyarakat) berupa $P$ Pelatihan Pembuatan Presentasi Interaktif Untuk Warga Dan Perangkat Desa Karangduren,Kec. Pakisaji, Kab. Malang.Melalui Kegiatan "PKM (Pengabdian Kepada Masyarakat) pada Desa Karangduren, Kec. Pakisaji, Kab. Malang ini dilakukan untuk membantu menyelesaikan permasalahan yang ada dalam penggunaan software microsoft office power point untuk pembuatan presentasi interaktif, sehingga permasalahan yang ada dalam pembuatan media presentasi yang menarik. Selain itu penyampian informasi dalam rapat maupun pengumuman yang ada di desa bisa disampaikan lebih menarik.
\end{abstract}

Kata kunci-Microsoft Office, Power Point, Iptek, Pelayanan Desa

\section{PENDAHULUAN}

$\mathrm{P}$ Banyak langkah penyelenggara negara dilakukan dalam rangka meningkatkan kualitas pelayanan pada masyarakat. Satu diantaranya ditempuh melalui peningkatan kualitas SDM aparaturnya. Namun demikian, oleh karena jumlahnya yang sangat besar dan tersebar di seluruh tanah air, maka tidaklah mungkin itu semua terjangkau program pemerintah yang dikhususkan untuk itu. Implementasi kebijakan pemerintah yang memiliki karakteristik seperti itu tidak akan berhasil tanpa didukung berbagai pihak, termasuk masyarakat Perguruan Tinggi. Kegiatan PKM (Pengabdian Kepada Masyarakat) ini merupakan respon para dosen terhadap kondisi tersebut.
Di tingkat desa, banyak kendala yang dihadapi aparatur pemerintahan desa dalam upaya memberikan pelayanan pada masyarakatnya. Satu diantaranya yang kini menonjol adalah hambatan yang terkait dengan kurangnya pengetahuan dan

keterampilan pemanfaatan teknologi informasi dan komunikasi, khususnya aplikasi program komputer yang mendukung. Didasari kenyataan itulah maka gagasan untuk melaksanakan kegiatan PKM (Pengabdian Kepada Masyarakat) berupa Pelatihan Administrasi Perkantoran Microsoft Office.

Wilayah Desa Karangduren terletak pada wilayah dataran $2500 \mathrm{~m}$ di tas permukaan laut dengan koordinat antra 2000, dengan luas $510.200 \mathrm{~km} 2$ atau 510,20 ha, dengan batasbatas wilayah sebagai berikut: 
1. Sebelah utara : Desa Kendalpayak Kecamatan Pakisaji

2. Sebelah Timur: Desa Pandanduro Kecamatan Bululawang

3. Sebalah Selatan : Desa Sutojayan Kecamatan Pakisaji

4. Sebelah Barat : Desa Pakisaji Kecamatan Pakisaji Pusat pemerintahan Desa Karangduren terletak di dusun

Golek RT. 02 RW. 03 dengan menempati areal lahan seluas 1,5 ha. Adapun jarak tempuh Desa Karangduren ke ibu kota kecamatan kurang lebih $2 \mathrm{~km}$ dapat ditempuh denlgan waktu 10 menit, sedang jarak tempuh ke ibu kota kabupaten Malang $8 \mathrm{~km}$ dengan waktu kurang lebih 50 menit.

Sebagai bangsa yang besar, Indonesia yang terdiri dari berbagai budaya merupakan modal pendukung untuk mencapai susksesnya pembangunan di desa, terutama sebagai modal dasar untuk mempromosikan diri desa dalam kancah persaingan tingkat local, daerah, nasional maupun internasional. Sumber daya social budaya di desa Karangduren dapat dilihat pada table berikut

Tabel 1. Daftar Sumber Daya Sosial Budaya di Desa Karangduren

\begin{tabular}{|l|l|l|l|}
\hline No. & $\begin{array}{c}\text { Uraian Sumber Daya } \\
\text { Sosial Budaya }\end{array}$ & Volume & \multicolumn{1}{|c|}{ Satuan } \\
\hline 1 & Kesenian Sakera & 1 & Kelompok \\
\hline 2 & Kesenian Kuda Lumping & 3 & Kelompok \\
\hline 3 & Banjari & 5 & Keelompok \\
\hline
\end{tabular}

Kegiatan "PKM (Pengabdian Kepada Masyarakat) pada Desa Karangduren Kec.Pakisaji ini dilakukan untuk membantu menyelesaikan permasalahan yang ada dalam penggunaan software aplikasi perkantoran, sehingga dalam kegiatan sehari-hari yang ada di desa dalam melayani keperluan administrasi masyarakat baik masalah persuratan, perijinan dll dapat dengan cepat terlayani . Dari permasalahan tersebut respon para civitas akademik Politeknik Negeri Malang, khususnya Jurusan Teknologi Informasi, Program Studi Teknik Informatika untuk membantu menyelesaikan permasalahan yang ada. Dengan memberikan "Pelatihan Administrasi Perkantoran Microsoft Office Untuk Warga dan Perangkat Desa Karangduren, Kec. Pakisaji, Kab. Malang.", sehingga warga masyarakat dan perangkat Desa Karangduren bisa memperoleh manfaat dari program Pengabdian Kepada Masyarakat ini.

\section{KAJIAN PUSTAKA}

\subsection{Definisi Multimedia}

Multimedia adalah suatu sarana (media) yang didalamnya terdapat perpaduan (kombinasi) berbagai bentuk elemen informasi, seperti teks, grafis, animasi, video, interaktif maupun suara sebagai pendukung untuk mencapai tujuannya yaitu menyampaikan informasi atau sekedar memberikan hiburan bagi target audiens-nya.

Multimedia sering digunakan dalam dunia hiburan seperti game. Kata multimedia itu sendiri berasal dari kata multi (Bahasa Latin) yang berarti banyak dan katamedia (Bahasa Latin) yang berarti sesuatu yang dipakai untuk menyampaikan sesuatu.

Multimedia dapat dikategorikan menjadi 2 macam, yaitu mulitimedia linier dan multimedia interaktif. Multimedia linier adalah suatu multimedia yang tidak dilengkapi dengan alat pengontrol apapun yang dapat dioperasikan oleh pengguna. Multimedia ini berjalan sekuensial (berurutan / lurus), contohnya : TV dan film. Sedangkan multimedia interaktif adalah suatu multimedia yang dilengkapi dengan alat

pengontrol (atau alat bantu berupa komputer, mouse, keyboard dan lain-lain) yang dapat dioperasikan oleh pengguna, sehingga pengguna dapat memilih apa yang diinginkan untuk proses selanjutnya. Contohnya seperti aplikasi game. Multimedia interaktif menggabungkan dan mensinergikan semua media yang terdiri dari teks, grafik, audio, dan interaktivitas (rancangan).

Multimedia dapat disajikan dalam beberapa metode, antara lain :

- Berbasis kertas (Paper-based), contoh : buku, majalah, brosur.

- Berbasis cahaya (Light-based), contoh : slideshows, transparansi.

- Berbasis suara (Audi-based), contoh : CD Players, tape recorder, radio.

- Berbasis gambar bergerak (Movingimage-based), contoh : televisi, VCR (Video Cassete Recorder, film. 
- Berbasis Digital (Digilatally-based), contoh: komputer.

\subsection{Pengertian Presentasi}

Presentasi merupakan kegiatan berbicara di depan orang banyak atau salah satu bentuk komunikasi. presentasi adalah topik pengajuan kegiatan, pendapat atau informasi kepada orang lain. Tidak seperti pidato lebih sering dibawakan dalam acara resmi dan acara politik, presentasi lebih sering dilakukan di bisnis pertunjukan.

Tujuan dari presentasi dari semua jenis, misalnya, untuk membujuk, untuk menginformasikan, atau untuk meyakinkan. Untuk menjadi baik menyajikan, orang sering belajar ahli presentasi. Juga, ada banyak pembicara terkenal yang sering diamati oleh orang-orang yang ingin tahu bagaimana berbicara di depan umum.

Berbicara keterampilan di depan penonton sangat penting bagi siapa pun yang ingin maju. Banyak presiden, manajer, tenaga penjualan, dan seorang guru yang menjadi terkenal melalui keterampilan yang sukses dan presentasinya. Presentasi memiliki beberapa tujuan umum, antara lain:

- Untuk memberi informasi. Ini tujuan umum presentasi, seperti menginformasikan ide, pemikiran, produk, program, atau topic tertentu.

- Untuk membujuk atau meyakinkan. Biasanya dibawakan oleh wiraniaga atau sales.

- Untuk memberikan hiburan, seperti oleh komedian atau atau penyiar radio/TV dalam acara hiburan.

- Untuk memotivasi, seperti oleh motivator atau atasan kepada bawahan, guru keada murid, dosen kepada mahasiswa, pelatih (trainer) kepada audiens pelatihan.

- Untuk memberi inspirasi.

- Untuk mempromosikan produk kepada calon pembeli.

\subsection{Manfaat Presentasi}

Presentasi yang memiliki beberapa manfaat selain untuk menyampaikan pesan kepada orang lain, manfaat- manfaat tersebut antara lain:
- $\quad$ Sebagai saran perolehan informasi dari pembicara presentasi kepada audiens

- $\quad$ Sebagai sarana media komunikasi antar 2 belah pihak yang efektif

- $\quad$ Sebagai sarana edukasi yang dapat menambah pengetahuan

- $\quad$ Sebagai sarana penjelas materi

- $\quad$ Sebagai media pertukaran gagasan serta ide dari kedua belah pihak

\subsection{Presentasi yang Baik dan Menarik}

Pembuatan presentasi yang asal-asalan akan membuat penilaian kurang baik oleh audiens dan tidak terlihat profesional. Dalam tahap pembuatan sebuah presentasi perlu diperhatikan beberapa hal. Berikut ini adalah beberapa hal yang perlu diperhatikan agar tampilan presentasi terlihat profesional sehingga audiens tidak bosan.

- Pergunakan desain yang konsisten. Hal ini bisa dilakukan dengan menggunakan slide master, sehingga layout, font, bulleting, dan animasi pergantian slide menjadi konsisten hingga akhir presentasi.

- Batasi jumlah baris dalam setiap slide. Jumlah baris dalam slide yang terlalu banyak menyebabkan silde tersebut menjadi terlalu penuh, sehingga teks menjadi kecil-kecil. Akibat yang lebih parah, auidense tidak akan mau mencerna informasi dalam slide tersebut. Sampaikan poin-poin pokok dalam setipa slide, kemudian andalah yang harus mengembangan dan membumbui ketika melakukan presentasi.

- Pergunakan warna teks dan latar belakang yang kontras sehingga keterbacaannya tinggi.

- Hindari penggunaan animasi dan sound effect yang glamor. Animasi dengan diiringi sound effect yang glamour justru menyebabkan presentasi anda tidak profesional, berkesan kekanak-kanakan, dan tidak serius.

- Pertimbangkan untuk membuat tomboltombol yang langsung menghantarkan pada slide tertentu, sehingga bisa melompat maju ataupun mundur tanpa harus melewati silde demi slide. Hal ini seringkali diperlukan. 
- Satu gambar memberikan puluhan kali lipat informasi, oleh karena itu jika memungkinkan ditampilkan secara grafis akan lebih baik ditampilkan secara grafis, misalnya tabel, skema, dll.

- Jika terlalu sering teks saja yang ditampilkan, berikan gambar-gambar ilustrasi yang sesuai untuk membumbui presentasi anda

\subsection{Microsoft Power Point}

Microsoft PowerPoint atau Microsoft Office PowerPoint atau PowerPoint adalah sebuah program komputer untuk presentasi yang dikembangkan oleh Microsoft di dalam paket aplikasi kantoran mereka, Microsoft Office, selain Microsoft Word, Excel, Access dan beberapa program lainnya. PowerPoint berjalan di atas komputer PC berbasis sistem operasi Microsoft Windows dan juga Apple Macintosh yang menggunakan sistem operasi Apple Mac OS, meskipun pada awalnya aplikasi ini berjalan di atas sistem operasi Xenix. Aplikasi ini sangat banyak digunakan, apalagi oleh kalangan perkantoran dan pebisnis, para pendidik, siswa, dan trainer. Dimulai pada versi Microsoft Office System 2003, Microsoft mengganti nama dari sebelumnya Microsoft PowerPoint saja menjadi Microsoft Office PowerPoint. Lalu, pada Office 2013, namanya cukup disingkat PowerPoint. Versi terbaru dari PowerPoint adalah versi 15 (Microsoft Office PowerPoint 2013), yang tergabung ke dalam paket Microsoft Office 2013.

\subsection{Infografis}

Setiap orang modern tentunya sangat akrab dengan informasi. Seringkali informasi yang disampaikan terlalu banyak dan kompleks. Untuk itu, bentuk-bentuk komunikasi visual yang mudah dipahami diperlukan untuk mengatasi kompleksitas informasi.

Salah satu metode dalam menyusun informasi agar lebih menarik untuk disimak yaitu dengan merancang sebuah infografis. Mungkin sobat pernah melihat tabel-tabel yang statis dan kaku seperti di Microsoft Excel. Dengan infografis tabel dan data diolah sedemikian rupa sehingga menghasilkan susunan data dan informasi yang lebih dinamis.

Infografis sering kita lihat di media massa cetak seperti surat kabar atau majalah dan media online. Saat ini, infografis mulai banyak digunakan untuk berbagai keperluan termasuk dalam penyusunan laporan, buku tahunan atau company profile.

\section{METODE PENELITIAN}

\subsection{Khalayak Sasaran}

Khalayak sasaran pengabdian masyarakat ini adalah warga masyarakat dan perangkat desa Pakisaji, Kec. Pakisaji, Kab. Malang

\subsection{Metode PPM}

Untuk mencapai sasaran, tahapan yang dilakukan dalam kegiatan pengabdian kepada masyarakat ini adalah:

a. Studi Lapangan

Tahap ini ditujukan untuk mendapatkan kebutuhan dari warga masyarakat dan perangkat desa Pakisaji. Pada tahap ini dilakukan wawancaara dengan pihak warga dan perangkat desa Pakisaji, Kec. Pakisaji, Kab. Malang untuk mensinkronkan rencana pengabdian dan kebutuan yang diinginkan. Hasil dari tahap ini berupa kesepakatan bentuk dan materi pelatihan.

b. Pembuatan Materi

Pada tahap ini dilakukan studi pustaka untuk merumuskan dan membuat materi pelatihan pembuatan website.

c. Pelaksanaan Pelatihan

Pelatihan dilakukan dengan cara ceramah dan praktek langsung. Komunikasi dua arah (interaksi tanya jawab) dilakukan untuk memperdalam dan lebih menguasai materi.

d. Evaluasi

Pada tahap ini dilakukan proses pengujian dari pelatihan yang telah dilakukan. Hal ini dilakukan dengan menentukan indikator keberhasilan dan mencocokkan dengan hasil pelatihan yang telah dilaksanakan. 
Urutan metode yang dilakukan dalam kegiatan pengabdian kepada masyarakat ini ditunjukkan pada Gambar 1.

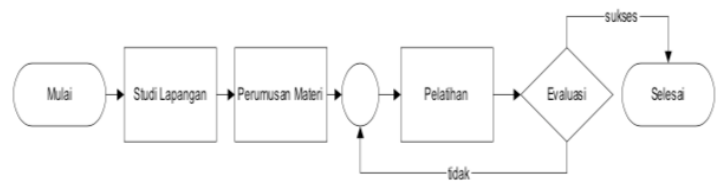

Gambar 1. Diagram Alir Kegiatan Pengabdian

\subsection{Rancangan Evaluasi}

Tahap evaluasi dilakukan melalui proses pengujian dari pelatihan dan pendampingan pembuatan website yang telah dilakukan pada warga masyarakat dan perangkat desa Pakisaji. Hal ini dilakukan dengan menentukan indikator keberhasilan dan mencocokkan dengan hasil pelatihan yang telah dilaksanakan. Indikator keberhasilan dapat diperlihatkan dengan adanya pembuatan website setelah pelatihan dilakukan

\section{PENGUJIAN}

Pelaksanaan kegiatan pelatihan dilaksanakan di balai desa Karang duren Kec. Pakisaji, Kab. Malang. Materi yang di berikan adalah materi tentang penggunaan software microsoft excel dalam menyelesaikan pekerjaan di desa Karangduren. Berikut materi pelatihan yang diberikan.

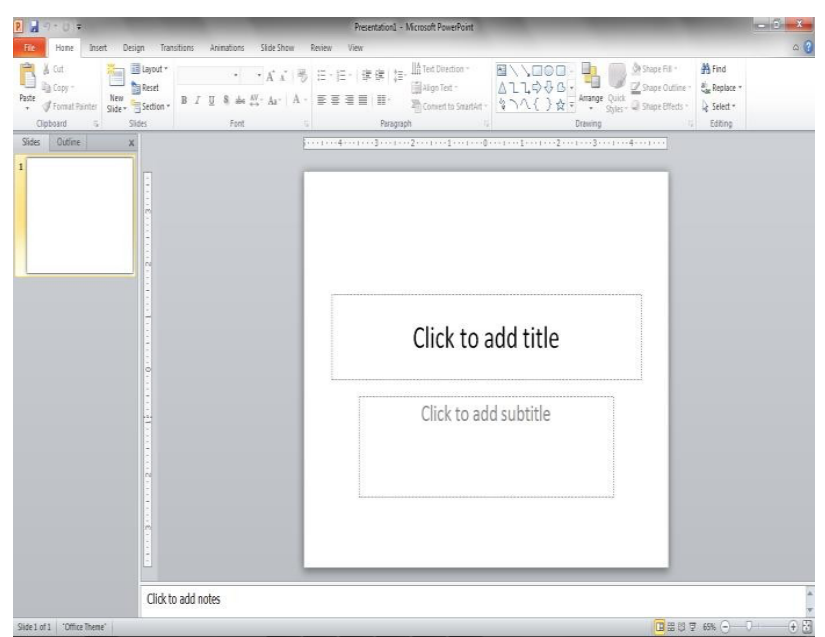

Gambar 2. Lembar kerja baru

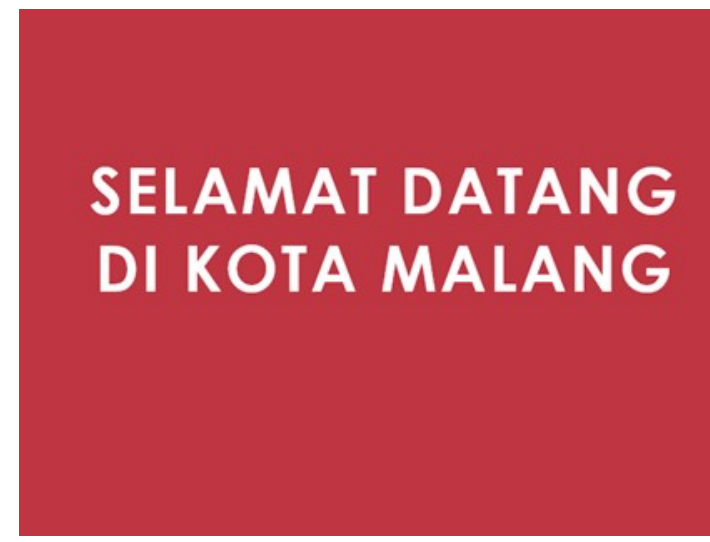

Gambar 3. Lembar Kerja Power Point

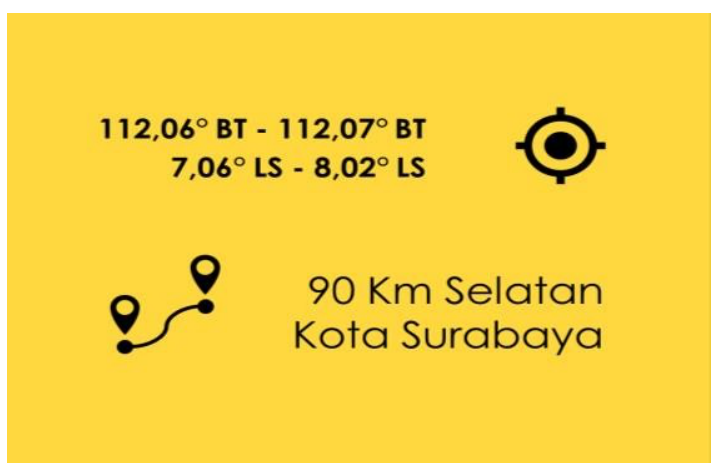

Gambar 4. Latihan Power Point

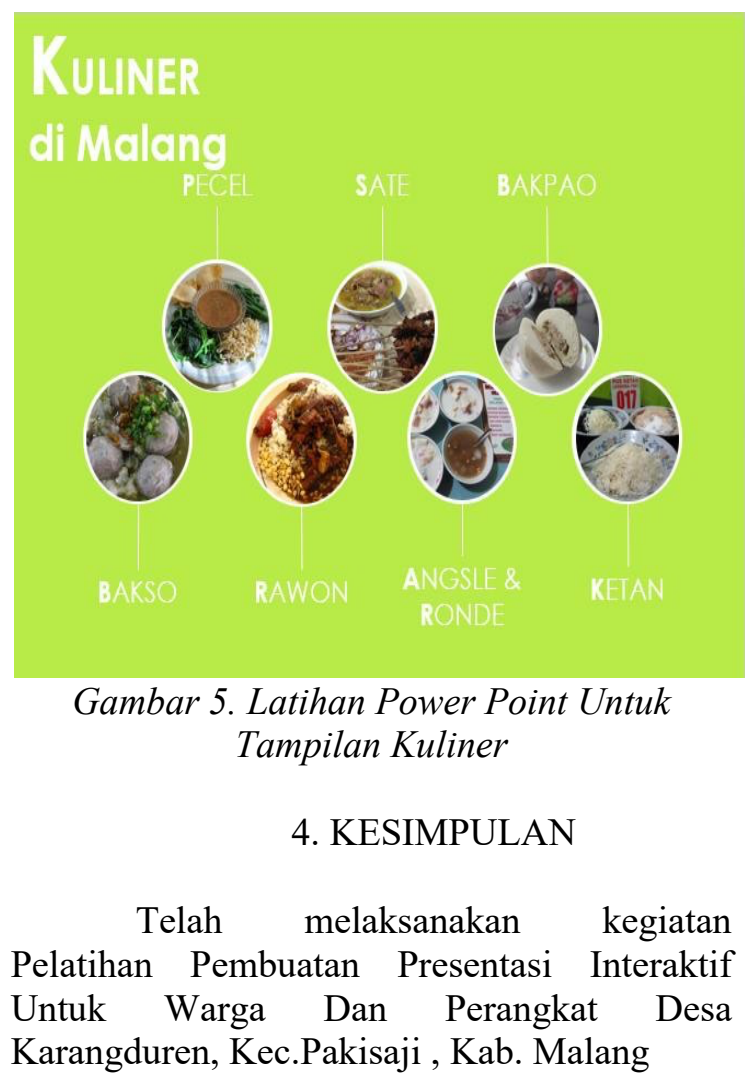


1. Dengan dukungan penuh dari bapak Kepala Desa, sehningga perangkat desa dan warga masyarakat mempunyai wawasan dan pengetahuan tentang penggunaan administrasi perkantoran menggunakan power point.

2. Dengan adanya ada kegiatan ini diharapkan kegiatan pembuatan presentasi interaktif pada kantor desa Karangduren berjalan dengan baik.

\section{DAFTAR PUSTAKA}

[1] Disnakkeswan, 2015. Bidang Produksi Targetkan Jumlah Ternak Meningkat. Disnakkeswan. Available at: http://petern Handayani, SB.; Martini, Ida. 2014. "Model Pemasaran Di Era New Wave Marketing". Jurnal Ekonomi Manajemen dan Akuntansi. No. 36 / Th. XXI / April 2014.

[2] Ikawanty, Beauty Anggraheny. 2015. "Otomatisasi Canting Listrik Untuk Pembuatan Batik Tulis Probolinggo". Prosiding SENTIA 2015, Politeknik Negeri Malang.

[3] Moriansyah, La. 2015. "Pemasaran Melalui Media Sosial: Antecedents Dan Consequences". Jurnal Penelitian Komunikasi dan Opini Publik Vol. 19 No.3, Desember 2015: 187-196

[4] Moyoretno, Bambang. Juni 2011. "Rancang Bangun Canting Elektrik". Dinamika Kerajinan dan Batik, Vol. 29. Yogyakarta.

[5] Nurficahyanti, Fera. 2015. "Model Komunikasi Pemasaran Paguyuban Batik Tulis". Jurnal Komunikasi ASPIKOM, Volume 2 Nomor 5, Juli 2015, hlm 304-313.

[6] Rif'ah, Mega Inayati; Wibisono, M. Arif. 2016. "Pengembangan Computer Aided Design (CAD) Warna Batik “. Jurnal Forum Teknik Vol. 37, No. 1, Januari 2016.

[7] Tahwin, Muhammad, 2012. "Pengembangan Industri Kecil (Studi Kasus Industri Bordir Kecamatan Sedan Kabupaten Rembang)". Jurnal POTENSIO Volume 17 No. 1 Juli 2012.
[8] Wibisono, Guntur; Susanto, Wahyu Eko. 2015. "Perancangan Website Sebagai Media Informasi Dan Promosi Batik Khas Kabupaten Kulonprogo". Jurnal Evolusi - Volume 32 No 2015. akan.malangkab.go.id/mobile/berita430.html [Accessed June 18, 2017].

[9] Polinema, 2016. Rencana Strategis Penelitian Politeknik Negeri Malang,

[10] Abdul kadir, 2003. Pemrograman Web, Penerbit Andi, Yogjakarta

[11] Jogiyanto, 2003.Sistem Teknologi Informasi, Penerbit Andi, Yogjakarta. 